\title{
Photovoltaic emulator of different solar array configurations under partial shading conditions using damping injection controller
}

\author{
Mustapha Alaoui' ${ }^{1}$, Hattab Maker ${ }^{2}$, Azeddine Mouhsen ${ }^{3}$, Hicham Hihi ${ }^{4}$ \\ ${ }^{1,2}$ Interdisciplinary Laboratory of Applied Sciences, ENSA of Berrechid, Hassan First University, Morocco \\ ${ }^{3}$ Laboratory of Radiation-Matter \& Instrumentation, FST of Settat, Hassan First University, Morocco \\ ${ }^{4}$ Laboratory of Engineering, Systems and Applications, ENSA of Fez, Sidi Mohamed Ben Abdellah University, Morocco
}

\begin{tabular}{l} 
Article Info \\
\hline Article history: \\
Received Sep 5, 2019 \\
Revised Dec 22, 2019 \\
Accepted Jan 8, 2020 \\
\hline Keywords: \\
Damping injection controller \\
DC-DC buck converter \\
Hybrid referencing \\
PV array configurations \\
PV array emulator \\
PV characteristics
\end{tabular}

\section{Corresponding Author:}

Mustapha Alaoui, Interdisciplinary Laboratory of Applied Sciences, ENSA of Berrechid, Hassan First University, Morocco.

Email: mu.alaoui@uhp.ac.ma

\begin{abstract}
In the last decades, researchers and scientists have been trending towards photovoltaic (PV) solar energy research as one of the noteworthy renewable energies. As a matter of fact, the need for a laboratory system devoted to performing measurements and experimentation on PV systems is being increased. The PV array emulator is designed to accomplish this task by reproducing accurately the electrical behavior of real PV sources. The present paper proposes thus a new control and design of PV array emulators. It is based essentially on a hybrid Damping Injection controller. The proposed control strategy circumvents obviously the existing PV emulator's limitations in terms of accuracy, speed and partial shading emulation. Several results are given and discussed to show the efficiency of the proposed system to emulate PV modules and different PV array configurations under uniform solar irradiance and partial shading conditions.
\end{abstract}

This is an open access article under the CC BY-SA license.

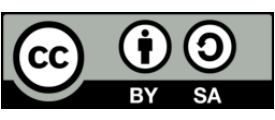

\section{INTRODUCTION}

In recent years, the interest in renewable and sustainable energy is being considerably increased, a growing awareness of the impact of conventional power generation resources on environment and human safety has been intensively remarked. Therefore, Contributing to sustainable development by reducing greenhouse gas emissions has become one of the important priorities of many countries around the world [1]. Photovoltaic solar energy is a green power resource widely used to produce clean electricity by using energy from the sun. Many researchers and scientists have devoted their research activities to the modeling of this PV energy, its optimization, its control and many other related fields. However, one of the most major problems hindering the progress and competitiveness of this renewable energy is the intermittent power production, which necessitates the use of storage techniques or energetic mix with other power sources. This problem not only impacts the commercial maturity and competitiveness of the PV solar energy, but also the research and development of PV energy systems [1]. Indeed, the intermittence and weather dependence of PV solar energy hinder researchers to carry out their experiments and measurements on PV systems without depending on atmospheric conditions of temperature and solar irradiance [1, 2]. The real-time experimentation on PV energy often needs repetitive tests at the desired climatic conditions to validate for instance Maximum Power Point Tracking (MPPT) algorithms and solar grid-connected inverters [1-4]. 
That's why, the need for a PV emulator system is inevitable, this laboratory device has to reproduce the electrical behavior of a real PV generator by tracking the current-voltage (I-V) characteristic without being dependent on weather conditions. It should reproduce the same current and voltage of actual PV sources at the desired temperature $(T)$ and irradiance $(G)$ that the user will define [1-3].

In the literature, many research studies have been performed regarding PV source emulators, they are in most case based on the switched-mode power supply (SMPS) since SMPS are more efficient than linear regulators [5-7]. The majority of proposed PV emulators suffer from inaccuracy and instability in some particular zones of the I-V characteristic of the PV module due to its nonlinearity, especially on the constant current and constant voltage zones [2]. Several control strategies of the PV emulator have been proposed to overcome these problems, such as perturb and observe method (P\&O), Hill Climbing technique (HC), Resistance Comparison Method [8-10]. However, all these methods require an iterative process to reach the operating point of the system, the iteration step is highly linked to the accuracy and the dynamic of the system, so when the iteration step is small, the system gets a good accuracy and less oscillation, but a poor dynamic response is observed, and when the iteration step is increased, the dynamic response is improved at the expense of accuracy [2]. The proposed control strategy does not require any iterative algorithm and ensures both good accuracy and high dynamic performances.

Furthermore, the commercial PV emulators utilizing programmable power supply have a poor dynamic response which can affect the efficiency of the emulation, especially with some algorithms like MPPT that need rapid emulation [2, 11]. Moreover, the need for PV emulation is not confined to PV modules, but the researchers usually need to emulate different PV array configurations such as series configuration, parallel configuration, total-cross-tied configuration... under uniform climatic conditions and partially shaded conditions [12]. According to the literature review, the emulation of PV array configurations under different scenarios of partial shading conditions is being rarely developed [2, 12]. Therefore, the proposed paper deals with all these limitations by designing a new PV source emulator based on a robust control strategy of Damping Injection which takes into consideration the nonlinearity of PV characteristics and produces, as a result, similar outputs as an actual PV array.

The developed PV array emulator is able to track faithfully the current and voltage of PV sources with high dynamic response and good accuracy for any operating point in the I-V curve and at any environmental conditions. The proposed PV system is based essentially on the one diode two resistances (1D-2R) PV model implemented in the Look-Up-Table (LUT), beside the DC-DC buck converter for the power part. The emulation algorithm based on hybrid referencing and damping injection control determines the operating point of the system and delivers, as a result, the required control signal to the power converter in order to track accurately the I-V characteristic curve.

\section{PROPOSED SYSTEM DESCRIPTION}

The proposed system is composed essentially of three parts which are: the power electronic converter, the reference generator and the controller. The power converter transmits the power to the load, it can be either a buck-converter, boost converter, SEPIC converter.

Buck converter topology has been chosen in this application since it ensures wide coverage of the PV characteristic curves from the short circuit to the open circuit operating points [13-15]. Besides, it has a simple structure with fewer components, the current and voltage ripples can be well-adjusted by choosing the right values of inductance $\mathrm{L}$ and capacitance C [16-19].

The current and voltage of the load are sensed and delivered to the second part which consists of the reference generator. The latest contains LUT where the PV characteristics are implemented.

LUT technique has been widely used in literature for PV emulator applications due to its simplicity and speed $[2,20]$. The number of data points of the LUT is chosen to have an accurate operating point localization without affecting the memory of the processor [1, 2, 21-23].

After generating the voltage and current references, which correspond to the operating point of the system, the Damping Injection (DI) controller takes over in order to track accurately the reference; if the operating point belongs to the constant current zone (CCZ), the first damping injection controller (DI1) will track the current reference, whereas if the operating point is at the constant voltage zone (CVZ), the second damping injection controller (DI2) will take over in order to track the voltage reference. This control strategy is well-detailed in the next section. The DI controller generates, as a result, the duty cycle $\mathrm{d}$ which will be used by the Pulse Width Modulation (PWM) technique to deliver the control signal $u$ of the power converter transistor as shown in Figure 1.

The simulation parameters of the PV emulator with the characteristics of the PV modules to emulate are presented in Tables 1 and 2.

Int J Pow Elec \& Dri Syst, Vol. 11, No. 2, June 2020 : 1019 - 1030 


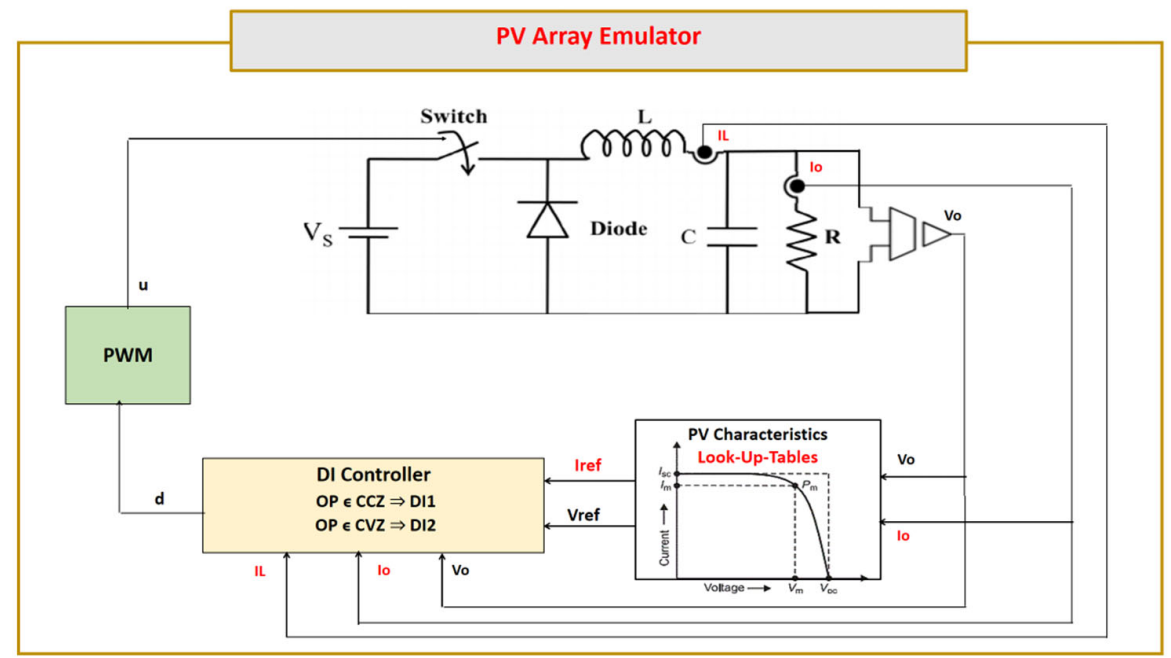

Figure 1. Overall structure of the proposed PV emulator

Table 1. PV Emulator Parameters

\begin{tabular}{cr}
\hline Variable & Value \\
\hline Input voltage $\mathrm{V}_{\mathrm{s}}$ & $150 \mathrm{~V}$ \\
Capacitor C & $10 \mu \mathrm{F}$ \\
Inductor L & $5 \mathrm{mH}$ \\
Switching frequency f & $50 \mathrm{KHz}$ \\
Controller gain R1 & 1000 \\
Controller gain R2 & 0.01 \\
\hline
\end{tabular}

Table 2. Datasheet Parameters of the Mono ALLMAX PLUS and Mono RENOGY PV Modules

\begin{tabular}{ccc}
\hline Variable & Mono ALLMAX PLUS PV module & Mono RENOGY PV module \\
\hline Peak rated power & $335 \mathrm{~W}$ & $50 \mathrm{~W}$ \\
Open circuit voltage $\mathrm{V}_{\mathrm{oc}}$ & $46.1 \mathrm{~V}$ & $22.6 \mathrm{~V}$ \\
Short circuit current $\mathrm{I}_{\mathrm{sc}}$ & $9.41 \mathrm{~A}$ & $2.92 \mathrm{~A}$ \\
Maximum power point voltage $\mathrm{V}_{\mathrm{mpp}}$ & $37.8 \mathrm{~V}$ & $18.5 \mathrm{~V}$ \\
Maximum power point current $\mathrm{I}_{\mathrm{mpp}}$ & $8.87 \mathrm{~A}$ & $2.71 \mathrm{~A}$ \\
Temperature coefficient of $\mathrm{I}_{\mathrm{sc}}: \mathrm{k}_{\mathrm{i}}$ & $0.053 \mathrm{~A} /{ }^{\circ} \mathrm{C}$ & $0.05 \mathrm{~A} /{ }^{\circ} \mathrm{C}$ \\
Temperature coefficient of $\mathrm{V}_{\mathrm{oc}}: \mathrm{k}_{\mathrm{v}}$ & $-0.31 \mathrm{~V} /{ }^{\circ} \mathrm{C}$ & $-0.31 \mathrm{~V} /{ }^{\circ} \mathrm{C}$ \\
Temperature coefficient of power: $\mathrm{k}_{\mathrm{p}}$ & $-0.41 \% /{ }^{\circ} \mathrm{C}$ & $-0.42 \% /{ }^{\circ} \mathrm{C}$ \\
Number of Cells in series Ns & 72 & 36 \\
\hline
\end{tabular}

The $\mathrm{L}$ and $\mathrm{C}$ values are chosen to operate in the continuous conduction mode, the controller gains are selected to ensure the desired dynamic and static performances, they can be tuned to change the dynamic behavior of the PV emulator. Furthermore, we have chosen two types of PV modules from two PV constructors in order to test different powers, the parameters are taken from the technical datasheets. The first one MONO ALLMAX module is used to validate the emulation of PV modules, while the second one MONO RENOGY is used for the emulation of PV arrays under partially shaded conditions.

\section{PROPOSED CONTROL STRATEGY OF THE PV EMULATOR}

In this part, a new control strategy of the PV array emulator is presented, it is based essentially on the passivity damping injection control, which uses an energetic approach and ensures a good dynamic response comparing to conventional linear compensators such as proportional integrator (PI) controller [17]. Besides, due to the nonlinearity of the PV characteristics, it is required the use of a specific nonlinear control strategy able to produce a stable and accurate PV emulator outputs irrespective of the operating point position, unlike direct referencing method which suffers from inaccuracy in some particular I-V curve areas $[2,24]$.

The proposed control strategy consists of a hybrid referencing method depending on the position of the operating point of the PV emulator as depicted in Figure 2. When the operating point is at the constant

Photovoltaic emulator of different solar array configurations under partial ... (Mustapha Alaoui) 
current region, the PV module current is approximately constant near to the short circuit current Isc, while the PV module voltage is highly variable. Therefore, a damping injection controller based on current referencing is recommended to guaranty a stable current loop as well as an accurate PV emulator outputs. On the other hand, if the operating point is at the constant voltage zone, the PV module voltage is almost constant near to the open-circuit voltage Voc. Therefore, a damping injection controller based on voltage referencing is suitable to have a stable reference voltage and thereby an accurate PV emulation. In order to locate the position of the operating point, a comparison between $\frac{\text { Vload }}{\text { Iload }}$ and $\frac{\text { Vmpp }}{\text { Imp } p}$ is required, with Vload and Iload are respectively the load voltage and current, and Vmpp and Impp are respectively the maximum power point voltage and current. We can also compare $\Delta \boldsymbol{V} \boldsymbol{p} \boldsymbol{v}$ to $\Delta \boldsymbol{I} \boldsymbol{p} \boldsymbol{v}$, where $\Delta \boldsymbol{V} \boldsymbol{p} \boldsymbol{v}$ and $\Delta \boldsymbol{I} \boldsymbol{p} \boldsymbol{v}$ are respectively the PV voltage and current variations if the PV characteristic presents more than one maximum power point.

It is worthy to note that the references are generated from the LUT. The data points of the LUT are calculated offline using the 1D2R mathematic model of the PV panel where the current and voltage are linked according to the following equation:

$$
\text { Iref }=I p h-I s\left[\exp \left(\frac{V o+R s * I r e f}{V t * A}\right)-1\right]-\frac{V o+R s * I r e f}{R p}
$$

With Iref is the PV current reference, Vo is the output voltage, Iph is the photoelectric current, Is is the diode saturation current, $\mathrm{Vt}$ is the junction thermal voltage, $\mathrm{A}$ is the diode ideality factor, Rs and $\mathrm{Rp}$ are respectively the PV module series and shunt resistances. The voltage reference is computed using the reverse I-V LUT, which is the V-I LUT.

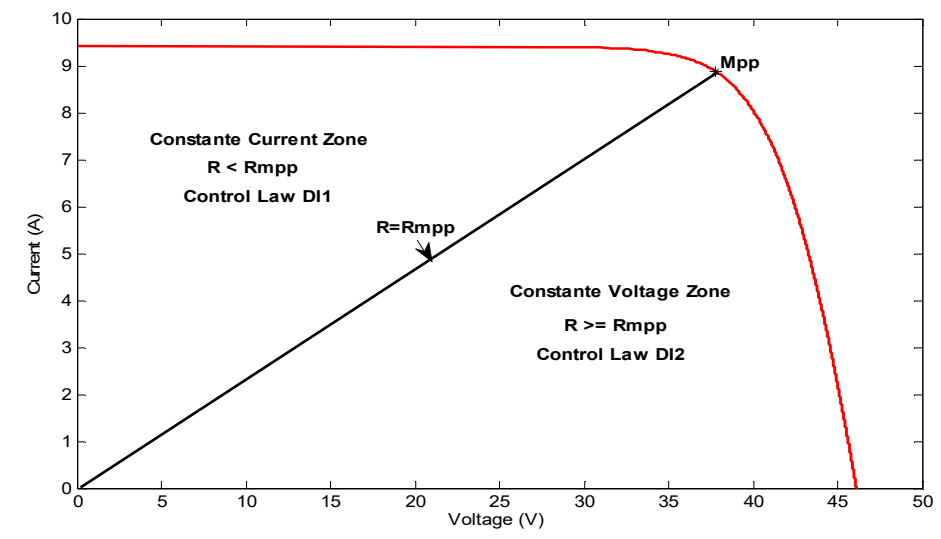

Figure 2. Control strategy of damping injection in function of the operating point location

Let's find the expressions of DI1 and DI2.

Euler Lagrange averaged state model of the buck converter is defined as [25]:

$$
\left(\begin{array}{ll}
L & 0 \\
0 & C
\end{array}\right) \dot{x}=\left(\begin{array}{cc}
0 & -1 \\
1 & -1 / R
\end{array}\right) x+u\left(\begin{array}{l}
E \\
0
\end{array}\right)
$$

With $\mathrm{x}$ is the state vector of the system $x=\left(\begin{array}{l}x 1 \\ x 2\end{array}\right)=\left(\begin{array}{c}I L \\ \text { Vload }\end{array}\right)=\left(\begin{array}{l}I L \\ \text { Vo }\end{array}\right)$

And $\mathrm{E}$ is the input voltage: $\mathrm{E}=\mathrm{Vs}$

It can be also written as:

$$
D \dot{x}-J x+\Re x=\mathbb{E}
$$

Where:

$$
D=\left(\begin{array}{ll}
\mathrm{L} & 0 \\
0 & \mathrm{C}
\end{array}\right) \text { Diagonal matrix containing the storage elements of the system; }
$$

Int J Pow Elec \& Dri Syst, Vol. 11, No. 2, June 2020 : 1019 - 1030 

components;

$J=\left(\begin{array}{cc}0 & -1 \\ 1 & 0\end{array}\right)$ Antisymmetric matrix representing the interconnection between the system system;

$$
\mathfrak{R}=\left(\begin{array}{cc}
0 & 0 \\
0 & 1 / \mathrm{R}
\end{array}\right) \text { Symmetric definite positive matrix representing the dissipative elements of the }
$$

$\mathbb{E}=u\left(\begin{array}{l}E \\ 0\end{array}\right)$ Contains the exogenous and control inputs of the system.

Considering the following desired Hamiltonian storage function:

$$
H d=\frac{1}{2} \check{x}^{T} D \check{x}
$$

With $\breve{x}=x-x d$ is the error and $\mathrm{xd}$ is the desired value of $\mathrm{x}$.

The desired damping $\mathfrak{R} d$ of the closed-loop is:

$$
\mathfrak{R d}=\mathfrak{R}+\mathfrak{R}_{D I}
$$

With $\Re_{D I}$ is the required damping to be injected so that $\Re d$ can be symmetric definite positive.

The dynamic of the error associated with the storage function $H d$ is defined as:

$$
D \dot{\check{x}}-J \check{x}+\Re d \check{x}=\Psi
$$

In order to have a passive and stable closed-loop, we can choose $\Psi=0$ [25]

The control law dynamic is then expressed as:

$$
D \dot{x d}-J x d+\mathfrak{R} x d-\mathfrak{R}_{D I} \check{x}=\mathbb{E}
$$

Let's choose $\mathfrak{R}_{D I}$ to be as:

$$
\Re_{D I}=\left(\begin{array}{cc}
R 1 & 0 \\
0 & R 2
\end{array}\right)
$$

$\mathrm{R} 1$ and $\mathrm{R} 2$ are two positive real numbers.

Thus:

$$
\Re_{d}=\left(\begin{array}{cc}
R 1 & 0 \\
0 & R 2+1 / R
\end{array}\right)
$$

Therefore:

$$
\left\{\begin{array}{c}
L x \dot{1} d+x 2 d-R 1(x 1-x 1 d)=u E \\
C x \dot{2} d-x 1 d+\frac{x 2 d}{R}-R 2(x 2-x 2 d)=0
\end{array}\right.
$$

\section{For the constant current region:}

Let's fix $x 1 d=$ Iref $=$ cte

Then from (10):

$$
\left\{\begin{array}{c}
x 2 d-R 1(x 1-\operatorname{Iref})=u E \\
C x \dot{2} d-\operatorname{Iref}+\frac{x 2 d}{R}-R 2(x 2-x 2 d)=0
\end{array}\right.
$$

Using (11) and (2):

$$
x \dot{2} d=\dot{u} E+R 1 \dot{1} 1=\dot{u} E+\frac{R 1 E}{L} u-\frac{R 1}{L} x 2
$$

Substituting $x \dot{2} d$ expression in (11), we find:

$$
C E \dot{u}+\frac{R 1 E C}{L} u-\frac{R 1 C}{L} x 2-I r e f+\left(\frac{1}{R}+R 2\right) x 2 d-R 2 x 2=0
$$


That yields replacing $\mathrm{x} 2 \mathrm{~d}$ by its expression from (11):

$$
C E \dot{u}+\left(\frac{R 1 E C}{L}+\frac{E}{R}+E R 2\right) u=\left(\frac{R 1 C}{L}+R 2\right) x 2-\left(\frac{R 1}{R}+R 1 R 2\right)(x 1-\text { Iref })+\text { Iref }
$$

Finally, the control law DI1 is expressed as:

$$
\mathrm{DI} 1: u=\frac{1}{\left(C E S+\frac{R 1 E C}{L}+\frac{E}{R}+E R 2\right)} *\left[\left(\frac{R 1 C}{L}+R 2\right) x 2-\left(\frac{R 1}{R}+R 1 R 2\right)(x 1-\text { Iref })+\text { Iref }\right]
$$

For the constant voltage region:

$\mathrm{x} 2 \mathrm{~d}=$ Vref $=$ cte

Then:

$$
\left\{\begin{array}{c}
L x \mathrm{i} d+\text { Vref }-R 1(x 1-x 1 d)=u E \\
-x 1 d+\frac{\text { Vref }}{R}-R 2(x 2-\text { Vref })=0
\end{array}\right.
$$

Using (16) and (2):

$$
x \dot{1} d=-R 2 \dot{2} 2=-\frac{R 2 x 1}{C}+\frac{R 2 x 2}{R C}
$$

Substituting the $\dot{x_{1 d}}$ expression in (16), we find:

$$
-L \frac{R 2}{C} x 1+L \frac{R 2}{R C} x 2+\operatorname{Vref}-R 1(x 1-x 1 d)=u E
$$

Then:

$$
-L \frac{R 2}{C} x 1+L \frac{R 2}{R C} x 2+V r e f-R 1\left(x 1-\frac{V r e f}{R}+R 2(x 2-\text { Vref })\right)=u E
$$

Finally, the control law DI2 is written as:

$$
\text { DI }: u=\frac{\frac{L R 2}{C}\left(\frac{x 2}{R}-x 1\right)-R 1\left(x 1-\frac{V r e f}{R}\right)-R 1 R 2(x 2-V r e f)+V r e f}{E}
$$

It is important to note that to avoid excessive switching between controllers when $\mathrm{R}$ is near to Rmpp, an overlap is made around the MPP $(\Delta R=2 \Omega)$ so the system in the MPP area can be controlled both by the DI1 or DI2. This frequent transition may be due to noise or measurement errors in practice.

\section{SIMULATION RESULTS AND DISCUSSION}

\subsection{Dynamic performances study}

\subsubsection{PV module emulator under dynamic loading}

In this part, in order to verify if the proposed system remains stable and accurate under changing the resistive load from an $\mathrm{I}-\mathrm{V}$ curve region to another, we have subjected the PV emulator to a rapid load variation profile which includes the constant current zone, the constant voltage zone and the MPP zone as depicted in Figure 3.

As shown in the above figure, it is obvious that the proposed PV system maintains its stability and accuracy even under varying the resistive load from an I-V region to another, the PV emulator tracks rapidly the PV module current and voltage, which proofs the robustness of the proposed control strategy.

Moreover, the static error is negligible around $1 \%$ and the current and voltage ripples are too small. Indeed, for $\mathrm{R}>=\mathrm{Rmpp}$, the current and voltage ripples factor is approximately $0.2 \%$, and for $\mathrm{R}<\mathrm{Rmpp}$, the current ripple factor increases slightly to $1,2 \%$ because of the output current increase. Overall, the PV emulator output ripples remain small for all the operating points.

Int J Pow Elec \& Dri Syst, Vol. 11, No. 2, June 2020 : 1019 - 1030 

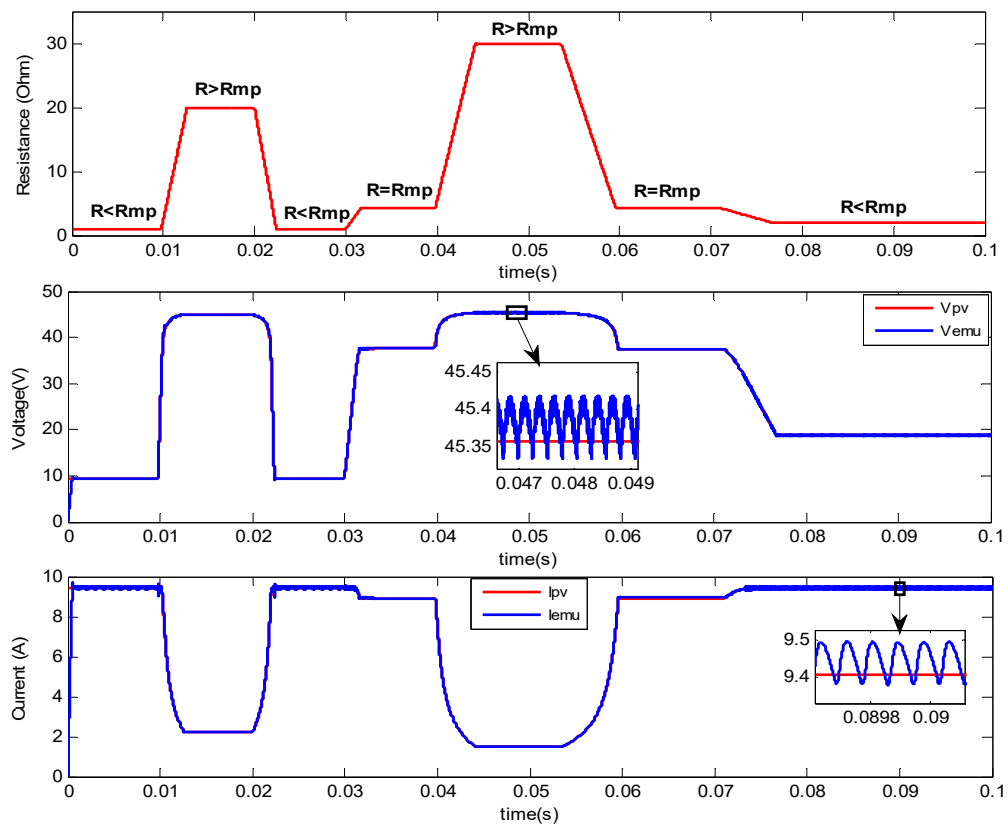

Figure 3. PV emulator outputs under changing the resistive load from I-V curve zone to another

\subsubsection{PV module emulator feeding resistive load at different $I-V$ curve zones}

The dynamic performances of the proposed PV module emulator are evaluated in this part. We have chosen three resistance loads, each one corresponds to one I-V curve zone. The operating points correspond to the intersection between the resistance characteristic with the I-V characteristic of the PV module. A comparison is done between the current and voltage of the PV emulator with the PV module's ones as shown in Figure 4.
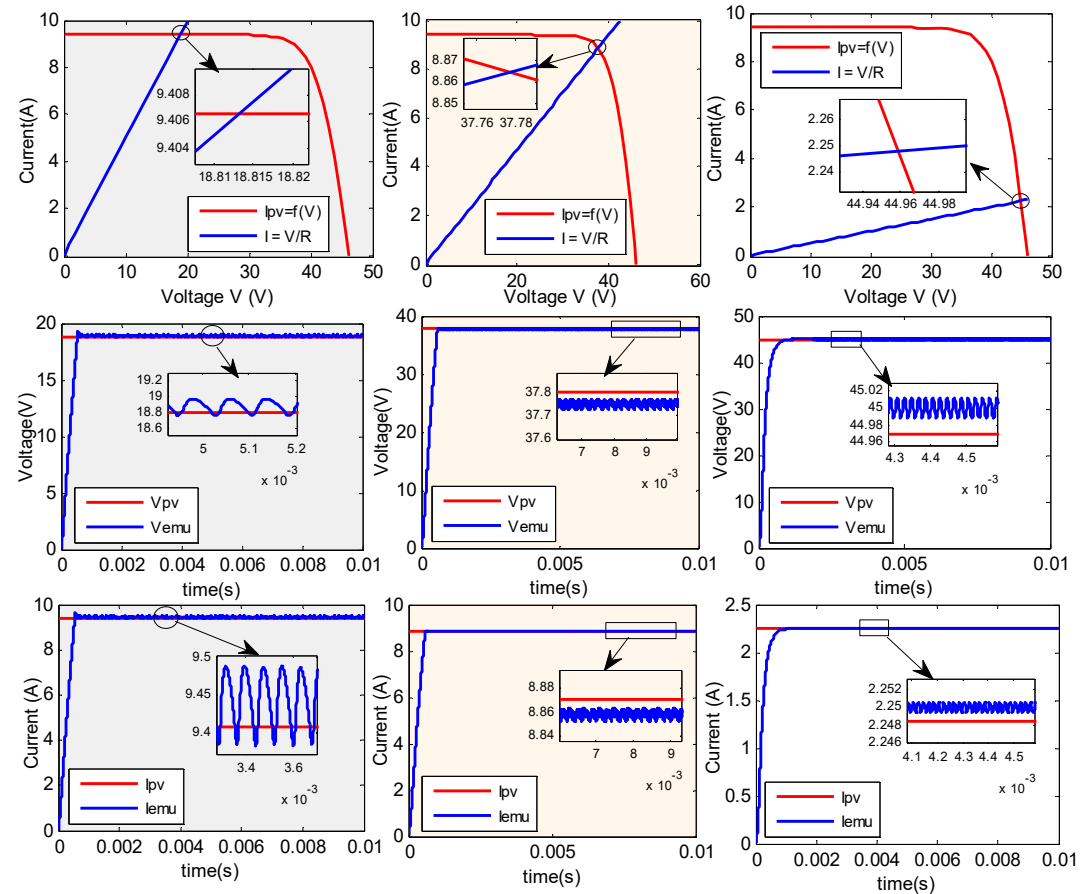

Figure 4. Dynamic response of the PV module emulator at the three I-V characteristic regions

Photovoltaic emulator of different solar array configurations under partial ... (Mustapha Alaoui) 
Figure 4 shows the dynamic performances of the proposed PV emulator, it contains three columns, and each column provides the I-V characteristic of the PV module with the resistive load characteristic, the PV model voltage with the PV emulator voltage, and the PV model current with the PV emulator current. The operating point at the constant current region corresponding to $R=2 \Omega$ is shown in the first column, while the second column shows an operating point at the Maximum power region $\left(R=\frac{V m p}{\operatorname{Imp}}\right)$. The third column includes an operating point at the constant voltage region $(\mathrm{R}=20 \Omega)$. PV emulator outputs are nearly the same as the PV model's ones, the relative static errors $e v=\frac{V p v-V e m u}{V p v}$ and $e i=\frac{I p v-I e m u}{I p v}$ are negligible not exceeding $1 \%$, the current and voltage ripples are around $1.5 \%$, whereas the settling time is too small between $600 \mu \mathrm{s}$ and $1 \mathrm{~ms}$, while the commercial PV emulators using programmable power supply have a dynamic performance between $10 \mathrm{~ms}$ to $100 \mathrm{~ms}$ [2]. Therefore, the designed PV emulator has a good dynamic performance compared to most of the existing PV emulators, the transient dynamic response is very rapid and the accuracy is very high. Besides, the proposed nonlinear power device is able to maintain its stability and accuracy in any I-V curve region, unlike existing PV emulators based on conventional control strategies that suffer from instability and inaccuracy in the constant current region and the constant voltage region [2].

\subsubsection{Solar emulator of several PV array configurations under partially shaded conditions}

In this section, several solar PV array configurations are proposed: Series, Parallel, Series-Parallel (SP), Honey-Comb (HC), Bridge-Linked (BL) and Total Cross-Tied (TCT) configurations. Each PV array configuration is subjected to a partial shading condition scenario as illustrated in Figure 5, which affects the $\mathrm{I}-\mathrm{V}$ and P-V characteristics of the PV array. The main objective of this part is to show the ability of the proposed PV array emulator to track the output current and voltage of the PV array for each solar PV configuration under partially shaded conditions and provide the same outputs.

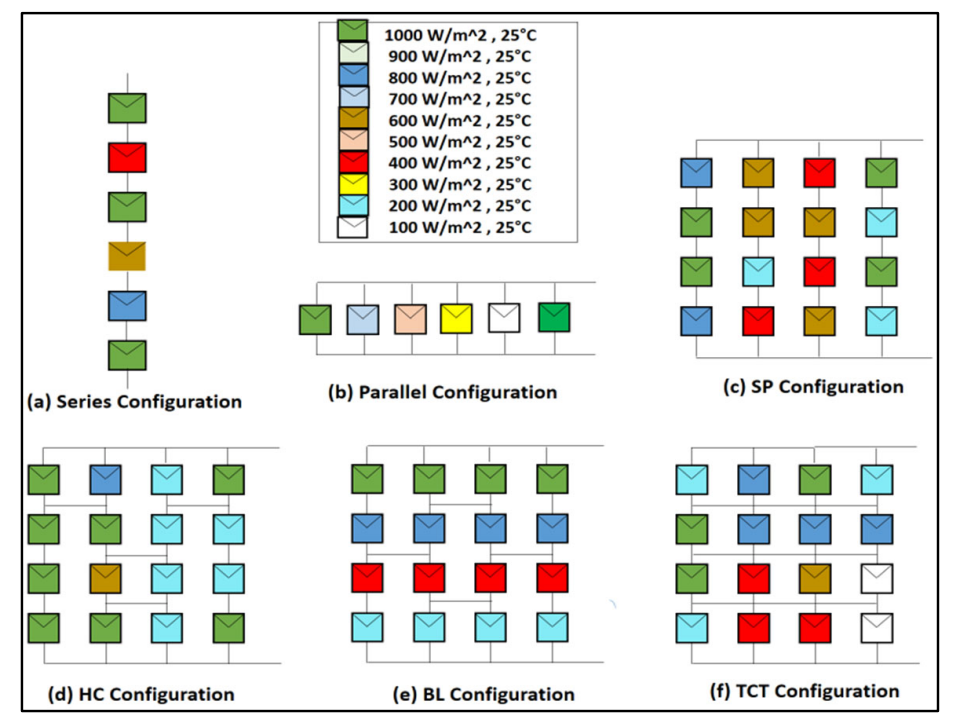

Figure 5. The different PV array configurations under partial shading conditions

Figures 6 and 7 show for each PV array configuration the I-V and P-V characteristic curve in the first and second waveforms of each column, and the output voltage and current of the PV array emulator and the PV array in the last waveforms of each PV configuration. The PV array emulator should deliver the same output current and voltage corresponding to the intersection point of the PV characteristics.

As described in Figures 6 and 7, we have chosen different resistive load values for each PV array configuration, the operating point is clearly shown for each case in the I-V and P-V characteristics. It can be concluded that the developed PV array emulator provides the same output current and voltage of the PV array for any PV array configuration under partial shading conditions. The coordinates of the operating points are the same as the PV emulator outputs. Note that the transient dynamic response is very fast since the settling time is around $500 \mu \mathrm{s}$ and can change slightly depending on the load value. Besides, since the

Int J Pow Elec \& Dri Syst, Vol. 11, No. 2, June 2020 : 1019 - 1030 
accuracy is the key feature that any PV emulator should ensure to mimic faithfully the PV source behavior, the accuracy of the proposed PV array emulator is very high because the static error remains very small irrespective of the PV array configuration, the partial shading condition and the load value, which constitutes an important added-value of the proposed power electronic system compared to the existing PV emulators.

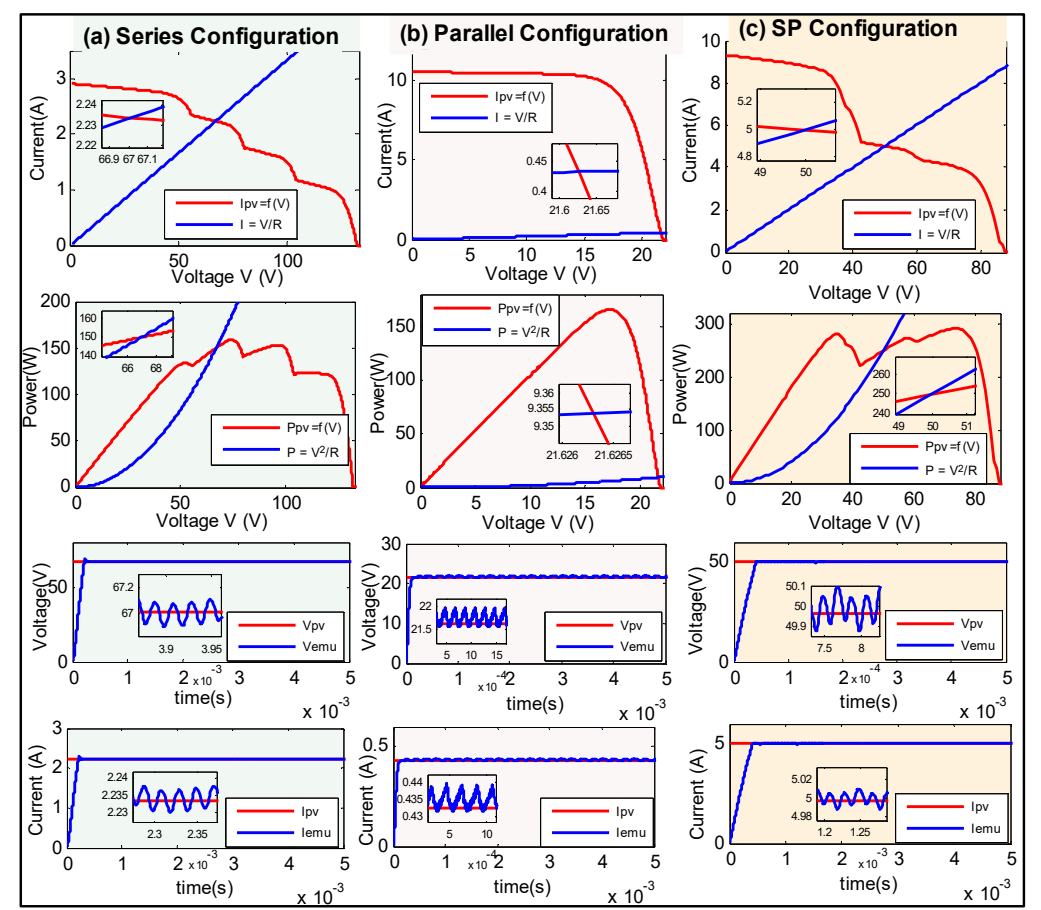

Figure 6. Dynamic response of the PV array emulator for series (a) parallel (b) and SP configurations (c)

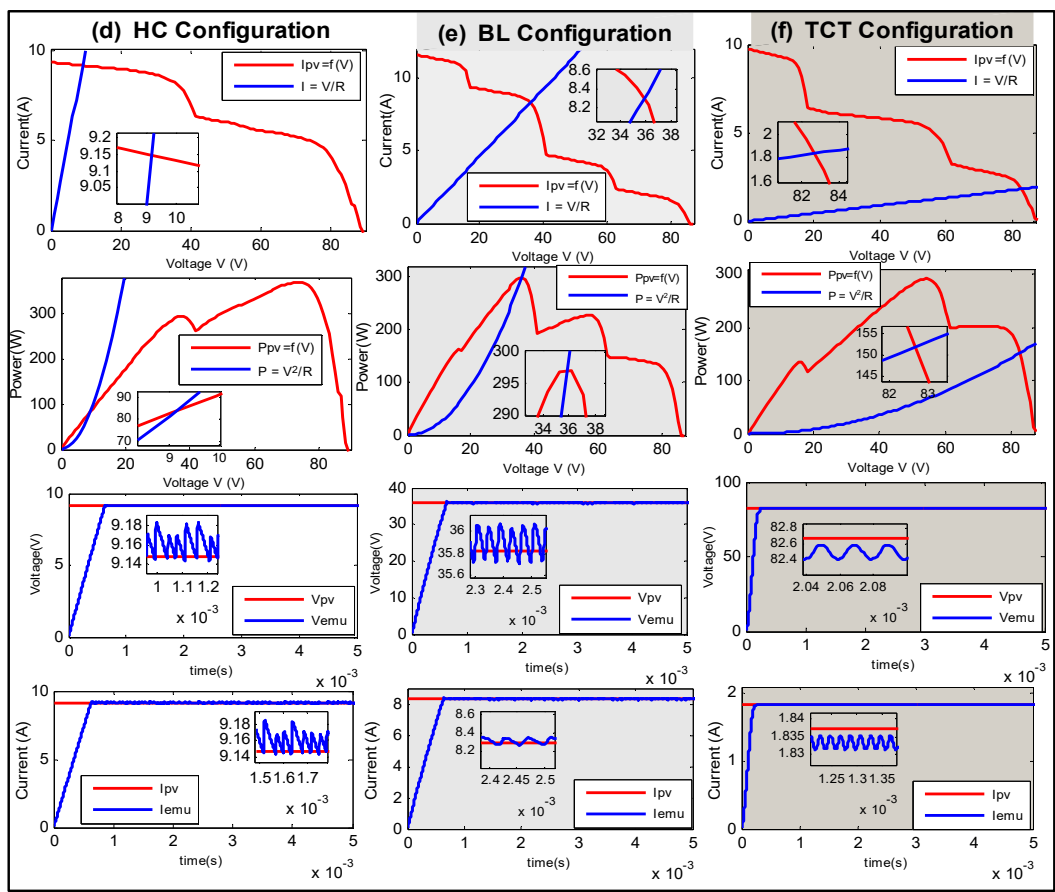

Figure 7. Dynamic response of the PV array emulator for HC (d) BL (e) and TCT configurations (f) 


\subsection{Static performance study}

This part attempts to investigate the static performances of the proposed PV array emulator. The resistance load had been varied in order to sweep all the I-V characteristic curve from the constant current region to the constant voltage region of the PV source. For each resistance value, the PV emulator current and voltage had been measured and compared to the PV source ones under different solar irradiance and temperature values. The first Figure 8 shows the I-V curves while the PV emulator is mimicking the PV module under different weather conditions, whereas the second Figure 9 presents the I-V curves in the case of emulating PV array configurations under partially shaded conditions.

According to Figures 8 and 9, the static performances of the proposed circuit meet the PV emulation requirements in terms of accuracy and the ability to emulate the whole I-V characteristics of different PV array configurations under partially shaded conditions. As highlighted in the figures below, the static error is very small not exceeding $1 \%$, which emphasizes the good accuracy of the PV emulator. Therefore, the user can choose the way to connect the PV modules, the desired weather parameters and the given partial shaded conditions, so the proposed system after getting the required information can provide the same PV array behavior at any time without needing to buy real PV panels or to have a large area for PV modules.

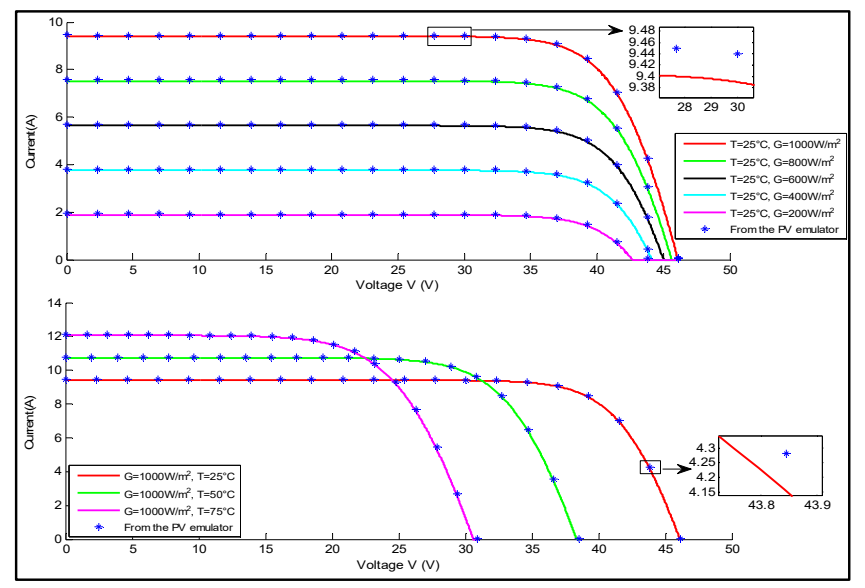

Figure 8. Comparison between I-V curves of the PV emulator and the PV module under different solar irradiances and ambient temperature
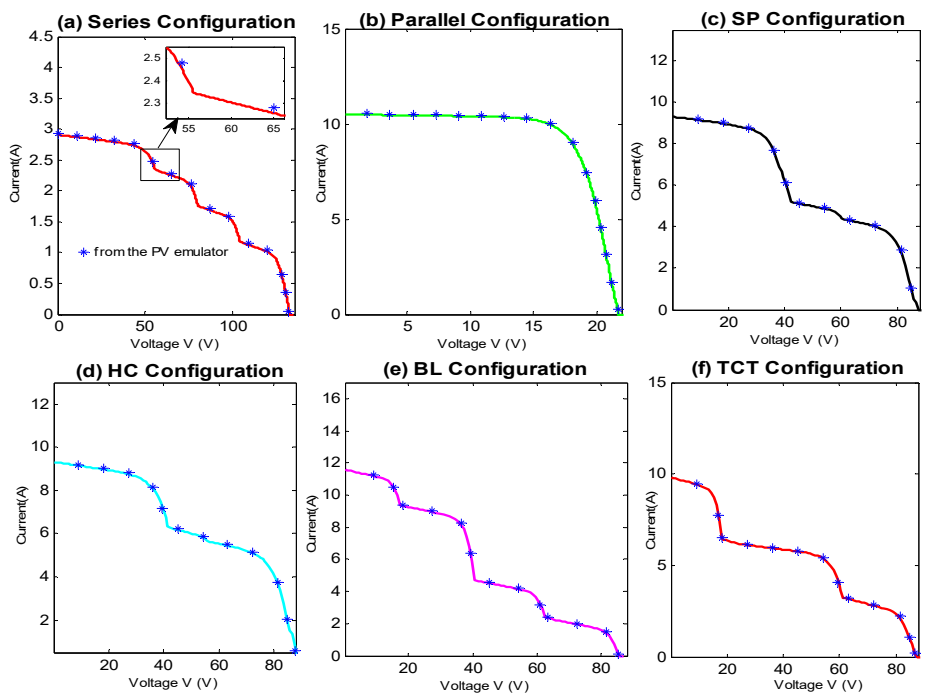

Figure 9. Comparison between I-V curves of the PV emulator and the PV array for different PV array configurations under partial shading conditions

Int J Pow Elec \& Dri Syst, Vol. 11, No. 2, June 2020 : $1019-1030$ 


\section{CONCLUSION}

This work has been dedicated to the photovoltaic emulation of PV modules and arrays. A new PV source emulator has been proposed, which consists mainly of the Damping Injection controller, LUT technique and DC-DC buck converter. Novel control strategy of referencing has been suggested and a deep analysis of the dynamic and static performances of the proposed power electronic circuit has been effected. Simulation results using Matlab-Simulink software show the effectiveness and usefulness of the designed circuit in producing the same current and voltage outputs as an actual PV source. Different PV array configurations have been used so as to investigate the ability of the PV emulator to track faithfully the I-V characteristics under different atmospheric conditions and partial shading conditions, the results have confirmed the good performances of the proposed system in terms of accuracy, stability, speed and overshoot limitation. Future work will be devoted to the experimental validation of the system and the test of MPPT algorithms connected to the PV emulator.

\section{REFERENCES}

[1] M. C. Di Piazza and G. Vitale, "Photovoltaic sources: modeling and emulation". London: Springer, 2013.

[2] R. Ayop and C. W. Tan, "A comprehensive review on photovoltaic emulator," Renewable and Sustainable Energy Reviews, vol. 80, pp. 430-452, Dec. 2017, doi: 10.1016/j.rser.2017.05.217.

[3] J. P. Ram, H. Manghani, D. S. Pillai, T. S. Babu, M. Miyatake, and N. Rajasekar, "Analysis on solar PV emulators: A review," Renewable and Sustainable Energy Reviews, vol. 81, pp. 149-160, Jan. 2018, doi: 10.1016/j.rser.2017.07.039.

[4] Z. Rasin, M. Fazlur Rahman, M. Azri, M. Hairul Nizam Talib, and A. Jidin, "Photovoltaic Emulator for Gridconnected Quasi-Z-Sorce Inverter," International Journal of Power Electronics and Drive Systems (IJPEDS), vol. 9, no. 4, p. 1976, Dec. 2018, doi: 10.11591/ijpeds.v9.i4.pp1976-1988.

[5] J. Zhang, S. Wang, Z. Wang, and L. Tian, "Design and Realization of a Digital PV Simulator with a Push-Pull Forward Circuit," Journal of Power Electronics, vol. 14, no. 3, pp. 444-457, May 2014, doi: 10.6113/JPE.2014.14.3.444.

[6] C. Chang, E. Chang, and H. Cheng, "A High-Efficiency Solar Array Simulator Implemented by an LLC Resonant DC-DC Converter," IEEE Transactions on Power Electronics, vol. 28, no. 6, pp. 3039-3046, Jun. 2013, doi: 10.1109/TPEL.2012.2205273.

[7] A. Castillo Atoche, J. Vázquez Castillo, J. Ortegón-Aguilar, R. Carrasco-Alvarez, J. Sandoval Gío, and A. ColliMenchi, "A high-accuracy photovoltaic emulator system using ARM processors," Solar Energy, vol. 120, pp. 389-398, Oct. 2015, doi: 10.1016/j.solener.2015.05.026.

[8] J. Gonzalez-Llorente, A. Rambal-Vecino, L. A. Garcia-Rodriguez, J. C. Balda, and E. I. Ortiz-Rivera, "Simple and efficient low power photovoltaic emulator for evaluation of power conditioning systems," in 2016 IEEE Applied Power Electronics Conference and Exposition (APEC), 2016, pp. 3712-3716, doi: 10.1109/APEC.2016.7468404.

[9] Ö. Özden, Y. Duru, S. Zengin, and M. Boztepe, "Design and implementation of programmable PV simulator," in 2016 International Symposium on Fundamentals of Electrical Engineering (ISFEE), 2016, pp. 1-5, doi: 10.1109/ISFEE.2016.7803229.

[10] R. Ayop, C. Wei Tan, and C. Siong Lim, "The Resistance Comparison Method Using Integral Controller for Photovoltaic Emulator," International Journal of Power Electronics and Drive Systems (IJPEDS), vol. 9, no. 2, p. 820, Jun. 2018, doi: 10.11591/ijpeds.v9.i2.pp820-828.

[11] A. Chalh, S. Motahhir, A. El Hammoumi, el ghzizal Abdelaziz, and A. Derouich, "Study of a Low-Cost PV Emulator for Testing MPPT Algorithm Under Fast Irradiation and Temperature Change," Technology and Economics of Smart Grids and Sustainable Energy, vol. 3, Dec. 2018, doi: 10.1007/s40866-018-0047-8.

[12] R. Ramaprabha and B. L. Mathur, "A Comprehensive Review and Analysis of Solar Photovoltaic Array Configurations under Partial Shaded Conditions," International Journal of Photoenergy, vol. 2012, pp. 1-16, 2012, doi: $10.1155 / 2012 / 120214$.

[13] C. Balakishan and S. Babu, "Development of a Microcontroller Based PV Emulator With Current Controlled DC/DC Buck Converter," International Journal of Renewable Energy Research (IJRER), vol. 4, no. 4, pp. 1049-1055, Dec. 2014.

[14] A. V. Rana and H. H. Patel, "Current Controlled Buck Converter based Photovoltaic Emulator," Journal of Industrial and Intelligent Information, vol. 1, no. 2, pp. 91-96, 2013, doi: 10.12720/jiii.1.2.91-96.

[15] K. D. Wilkie, M. P. Foster, D. A. Stone, and C. M. Bingham, "Hardware-in-the-loop tuning of a feedback controller for a buck converter using a GA," in 2008 International Symposium on Power Electronics, Electrical Drives, Automation and Motion, Ischia, Italy, 2008, pp. 680-684, doi: 10.1109/SPEEDHAM.2008.4581265.

[16] S. M. Azharuddin et al., "A Near Accurate Solar PV Emulator Using dSPACE Controller for Real-time Control," Energy Procedia, vol. 61, pp. 2640-2648, 2014, doi: 10.1016/j.egypro.2014.12.266.

[17] I. Moussa and A. Khedher, "Photovoltaic emulator based on PV simulator RT implementation using XSG tools for an FPGA control: Theory and experimentation," International Transactions on Electrical Energy Systems, vol. 29, no. 8, p. e12024, 2019, doi: 10.1002/2050-7038.12024.

[18] M. Alaoui, H. Maker, and A. Mouhsen, "An Accurate Photovoltaic Source Emulator with High-Bandwidth Using a Backstepping Controller," in 2019 4th World Conference on Complex Systems (WCCS), 2019, pp. 1-6, doi: 10.1109/ICoCS.2019.8930786. 
[19] M. Alaoui, H. Maker, A. Mouhsen, and H. Hihi, "Emulation of Different Photovoltaic Materials and Technologies using PV Array Emulator with Linear Quadratic Regulator," International Journal of Scientific \& Technology Research (IJSTR), vol. 8, no. 11, p. 6, 2019.

[20] R. Ayop and C. W. Tan, "Rapid Prototyping of Photovoltaic Emulator Using Buck Converter Based on Fast Convergence Resistance Feedback Method," IEEE Transactions on Power Electronics, vol. 34, no. 9, pp. 8715-8723, Sep. 2019, doi: 10.1109/TPEL.2018.2886927.

[21] M. Hasnaoui, A. B.-B. Abdelghani, and I. Slama-Belkhodja, "Implementation of a PV Panel Model based on the Look-up Tables Method for a PV Generator Emulator," p. 6, 2016.

[22] J. Zhao and J. W. Kimball, "A digitally implemented photovoltaic simulator with a double current mode controller," in 2012 Twenty-Seventh Annual IEEE Applied Power Electronics Conference and Exposition (APEC), 2012, pp. 53-58, doi: 10.1109/APEC.2012.6165798.

[23] J. Chavarría, D. Biel, F. Guinjoan, A. Poveda, F. Masana, and E. Alarcón, "FPGA-based design of a step-up photovoltaic array emulator for the test of PV grid-connected inverters," in 2014 IEEE 23rd International Symposium on Industrial Electronics (ISIE), 2014, pp. 485-490, doi: 10.1109/ISIE.2014.6864661.

[24] M. Alaoui, H. Maker, A. Mouhsen, and H. Hihi, "Solar Photovoltaic Emulation Under Uniform Irradiance And Partial Shading Conditions Using Fuzzy Logic Control," International Journal of Scientific \& Technology Research (IJSTR), vol. 8, no. 11, p. 7, 2019.

[25] A. Jaafar, "Contribution à la modélisation, l'analyse et l'optimisation de lois de commande pour convertisseurs DCDC de puissance," Nov. 2011.

Int J Pow Elec \& Dri Syst, Vol. 11, No. 2, June 2020 : 1019-1030 